DOI: https://doi.org/10.24297/jam.v20i.9078

\title{
Metallic Ratios and Pascal's Triangle : Triads of Metallic Means in the Pascal's Triangle
}

\author{
Dr. Chetansing Rajput \\ M.B.B.S. Nair Hospital (Mumbai University) India, \\ Asst. Commissioner (Govt. of Maharashtra) \\ Email: chetansingkrajput@gmail.com \\ Website: https://goldenratiorajput.com/ \\ Lecture Link 1 : https://youtu.be/74uF4sBqYjs \\ Lecture Link 2 : https://youtu.be/vBfVDaFnA2k \\ Lecture Link 3 : https://youtu.be/raosniXwRhw \\ Lecture Link 4 : https: / youtu.be/Qh2B1tMl8Bk
}

\begin{abstract}
This paper introduces the close correspondence between Pascal's Triangle and the recently published mathematical formulae those provide the precise relations between different Metallic Ratios. The precise correlations between various Metallic Means can be substantiated with Pascal's Triangle, as described herein.
\end{abstract}

Keywords: Metallic Mean, Pythagoras Theorem, Fibonacci, Pell, Lucas, Pi, Phi, Silver Ratio, Right Triangle, Metallic Numbers, Metallic Ratio Triads, 36 9, Pythagorean Triples, Bronze Ratio, Golden Ratio, Pascal's Triangle, Metallic Ratio

\section{Introduction}

The renowned Pascal's Triangle, having the binomial coefficients in its rows and the Fibonacci Numbers in its shallow diagonals, is much celebrated in algebra, probability theory, and combinatorics.

However, more importantly, now it has been observed that this intriguing Triangular array of numbers also highlights the precise mathematical relations between different Metallic Ratios.

The Mathematical Formulae those provide the precise relations between different Metallic Means have been recently published in the works mentioned in References [1] and [2].

It is also observed that the precise correlations between various Metallic Means given by those formulae, can also be substantiated with Pascal's Triangle.

The prime objective of this work is to bring together this Pascal's Triangle and a recently published formula that provides the accurate mathematical relations between different Metallic Means. 
As a brief introduction, each Metallic Mean $\boldsymbol{\delta}_{\mathbf{n}}$ is the root of the simple Quadratic Equation $\mathbf{X}^{\mathbf{2}}-\mathbf{n} \mathbf{X}-\mathbf{1}=\mathbf{0}$, where $\mathbf{n}$ is any positive natural number.

Thus, the fractional expression of the $n^{\text {th }}$ Metallic Ratio is $\boldsymbol{\delta}_{n}=\frac{\mathbf{n}+\sqrt{\mathbf{n}^{2}+\mathbf{4}}}{\mathbf{2}}$

Moreover, each Metallic Ratio can be expressed as the continued fraction:

$\boldsymbol{\delta}_{\mathbf{n}}=\mathbf{n}+\frac{\mathbf{1}}{\mathbf{n}+\frac{\mathbf{1}}{\mathbf{n}+\frac{1}{\mathbf{n}+\ldots}}} ;$ And hence, $\boldsymbol{\delta}_{\mathbf{n}}=\mathbf{n}+\frac{\mathbf{1}}{\boldsymbol{\delta} \mathbf{n}}$

...References: [3], [4], [5]

\section{MATHEMATICAL CORRELATIONS AMONG DIFFERENT METALLIC RATIOS :}

If $\mathbf{K}, \mathbf{m}$ and $\mathbf{n}$ are three positive integers such that $\mathbf{n}$ is the smallest of the three integers and $\frac{\mathbf{m n}+\mathbf{4}}{\mathbf{m}-\mathbf{n}}=\mathbf{k}$

then, it is observed that

$\frac{\boldsymbol{\delta}_{\mathrm{m}} \times \boldsymbol{\delta}_{\mathrm{n}}+\mathbf{1}}{\boldsymbol{\delta}_{\mathrm{m}}-\boldsymbol{\delta}_{\mathrm{n}}}=\boldsymbol{\delta}_{\mathrm{k}}$ where $\boldsymbol{\delta}_{\mathrm{k}}, \boldsymbol{\delta}_{\mathrm{m}}$ and $\boldsymbol{\delta}_{\mathrm{n}}$ are the $\mathrm{k}^{\text {th }}, \mathrm{m}^{\text {th }}$ and $\mathrm{n}^{\text {th }}$ Metallic Means respectively.

This explicit formula, among several other formulae those give the precise mathematical relations between different Metallic Means, has been recently published in the works mentioned in References [1] and [2].

\section{The "TRIADS" Of Metallic Means :}

The abovementioned explicit formula gives the "Triads" of Metallic Means as $\left[\boldsymbol{\delta}_{\mathrm{n}}, \boldsymbol{\delta}_{\mathrm{m}}, \boldsymbol{\delta}_{\mathrm{k}}\right]$

Where $\frac{\mathbf{m n}+4}{\mathbf{m}-\mathbf{n}}=\mathbf{k}$ and $\frac{\mathbf{k n}+4}{\mathrm{k}-\mathrm{n}}=\mathbf{m}$

hence, $\frac{\boldsymbol{\delta}_{\mathrm{m}} \times \boldsymbol{\delta}_{\mathrm{n}}+\mathbf{1}}{\boldsymbol{\delta}_{\mathrm{m}}-\boldsymbol{\delta}_{\mathrm{n}}}=\boldsymbol{\delta}_{\mathrm{k}}$ and also $\frac{\boldsymbol{\delta}_{\mathrm{k}} \times \boldsymbol{\delta}_{\mathrm{n}}+\mathbf{1}}{\boldsymbol{\delta}_{\mathrm{k}}-\boldsymbol{\delta}_{\mathrm{n}}}=\boldsymbol{\delta}_{\mathrm{m}}$

Moreover,

$$
\frac{\mathbf{k m}-4}{\mathbf{k}+\mathbf{m}}=\mathbf{n} \quad \text { and } \quad \frac{\boldsymbol{\delta}_{\mathrm{k}} \times \boldsymbol{\delta}_{\mathrm{m}}-\mathbf{1}}{\boldsymbol{\delta}_{\mathrm{k}}+\boldsymbol{\delta}_{\mathrm{m}}}=\boldsymbol{\delta}_{\mathbf{n}}
$$

For example, if $n=6$, the three integers 6,11 and 14 satisfy the prerequisite $\frac{\mathbf{m n}+\mathbf{4}}{\mathbf{m}-\mathbf{n}}=\mathbf{k}$; Hence, the three Metallic means $\boldsymbol{\delta}_{6}, \boldsymbol{\delta}_{11}$ and $\boldsymbol{\delta}_{14}$ form a Triad $\left[\boldsymbol{\delta}_{6}, \boldsymbol{\delta}_{11}, \boldsymbol{\delta}_{14}\right]$ such that :

$$
\frac{\boldsymbol{\delta}_{11} \times \boldsymbol{\delta}_{6}+\mathbf{1}}{\boldsymbol{\delta}_{11}-\boldsymbol{\delta}_{6}}=\boldsymbol{\delta}_{14} \quad \text { and } \quad \frac{\boldsymbol{\delta}_{14} \times \boldsymbol{\delta}_{6}+\mathbf{1}}{\boldsymbol{\delta}_{14}-\boldsymbol{\delta}_{6}}=\boldsymbol{\delta}_{11} \quad \text { and also } \quad \frac{\boldsymbol{\delta}_{14} \times \boldsymbol{\delta}_{11}-\mathbf{1}}{\boldsymbol{\delta}_{14}+\boldsymbol{\delta}_{11}}=\boldsymbol{\delta}_{\mathbf{6}}
$$


Noticeably, $\mathbf{n}=\mathbf{6}$ forms such multiple triads:

\begin{tabular}{|l|l|l|l|l|l|l|l|l|}
\hline$n$ & 6 & 6 & 6 & 6 & 6 & 6 & 6 & 6 \\
\hline $\mathrm{m}$ & 7 & 8 & 10 & 11 & 14 & 16 & 26 & 46 \\
\hline $\mathrm{k}$ & 46 & 26 & 16 & 14 & 11 & 10 & 8 & 7 \\
\hline
\end{tabular}

\section{: Shaded Triads have been exemplified above.}

And, just like $\mathbf{n}=\mathbf{6}$ exemplified above, every integer forms such multiple triads:

For example, $\mathbf{n}=\mathbf{1 0}$

\begin{tabular}{|l|l|l|l|l|l|l|l|l|}
\hline $\mathrm{n}$ & 10 & 10 & 10 & 10 & 10 & 10 & 10 & 10 \\
\hline $\mathrm{m}$ & 11 & 12 & 14 & 18 & 23 & 36 & 62 & 114 \\
\hline $\mathrm{k}$ & 114 & 62 & 36 & 23 & 18 & 14 & 12 & 11 \\
\hline
\end{tabular}

\section{Noticeably, Odd $\mathbf{n}$ forms Fewer Triads}

\begin{tabular}{|l|l|l|l|l|l|l|l|l|}
\hline $\mathrm{n}$ & 5 & 5 & 5 & 5 & 5 & 5 & 5 & 5 \\
\hline $\mathrm{m}$ & 6 & 34 & & & & & & \\
\hline $\mathrm{k}$ & 34 & 6 & & & & & & \\
\hline
\end{tabular}

It may be noticed from above Table that every $\mathrm{n}^{\text {th }}$ Metallic Mean can give precise values of various Metallic Means by the formula $\frac{\boldsymbol{\delta}_{\mathrm{m}} \times \boldsymbol{\delta}_{\mathrm{n}}+\mathbf{1}}{\boldsymbol{\delta}_{\mathrm{m}}-\boldsymbol{\delta}_{\mathrm{n}}}=\boldsymbol{\delta}_{\mathrm{k}}$, maximum upto $\left(\mathrm{n}^{2}+\mathrm{n}+4\right)^{\text {th }}$ Metallic Mean:

$m_{\max }=k_{\max }=\left(n^{2}+n+4\right)$

Also noticeably, the Even Integers $\left(\right.$ Even $\mathrm{n}_{\mathrm{s}}$ ) form comparatively more Triads than the Odd $\mathrm{n}_{\mathrm{s}}$. Several such patterns about these Triads of Metallic Means have been discussed in detail in the works mentioned in References [2] and [1]. Here, let us consider the close correspondence of the abovementioned Formula and TRIADS with the Pascal's Triangle.

\section{Metallic Ratios and the Pascal's Triangle :}

The abovementioned Formula and the TRIADS can be substantiated with the Pascal's Triangle, as follows.

Consider the integers $\mathbf{n}$ and $\mathbf{m}$ on the "Natural Numbers Diagonal" of the Pascal's Triangle, the precise value of $\mathbf{k}$ can be derived from the "Triangular Numbers Diagonal" of the Pascal's Triangle. 


\section{"TRIADS" of Metallic Means}

Where $\frac{\mathbf{m n}+\mathbf{4}}{\mathbf{m}-\mathbf{n}}=\mathbf{k} \quad$ and $\quad \frac{\mathbf{k n}+\mathbf{4}}{\mathrm{k}-\mathbf{n}}=\mathbf{m}$

hence, $\frac{\boldsymbol{\delta}_{\mathrm{m}} \times \boldsymbol{\delta}_{\mathrm{n}}+\mathbf{1}}{\boldsymbol{\delta}_{\mathrm{m}}-\boldsymbol{\delta}_{\mathrm{n}}}=\boldsymbol{\delta}_{\mathrm{k}} \quad$ and also $\quad \frac{\boldsymbol{\delta}_{\mathrm{k}} \times \boldsymbol{\delta}_{\mathrm{n}}+\mathbf{1}}{\boldsymbol{\delta}_{\mathrm{k}}-\boldsymbol{\delta}_{\mathrm{n}}}=\boldsymbol{\delta}_{\mathrm{m}}$

And also, $\quad \frac{\mathbf{k m}-\mathbf{4}}{\mathbf{k}+\mathbf{m}}=\mathbf{n} \quad$ and $\quad \frac{\boldsymbol{\delta}_{\mathrm{k}} \times \boldsymbol{\delta}_{\mathrm{m}}-\mathbf{1}}{\boldsymbol{\delta}_{\mathrm{k}}+\boldsymbol{\delta}_{\mathrm{m}}}=\boldsymbol{\delta}_{\mathbf{n}}$

These TRIADS in Pascal's Triangle

$m$ and $n$ from the Natural Numbers Diagonal

then,

\section{Triangular Numbers Diagonal gives value of $\mathbf{k}$}

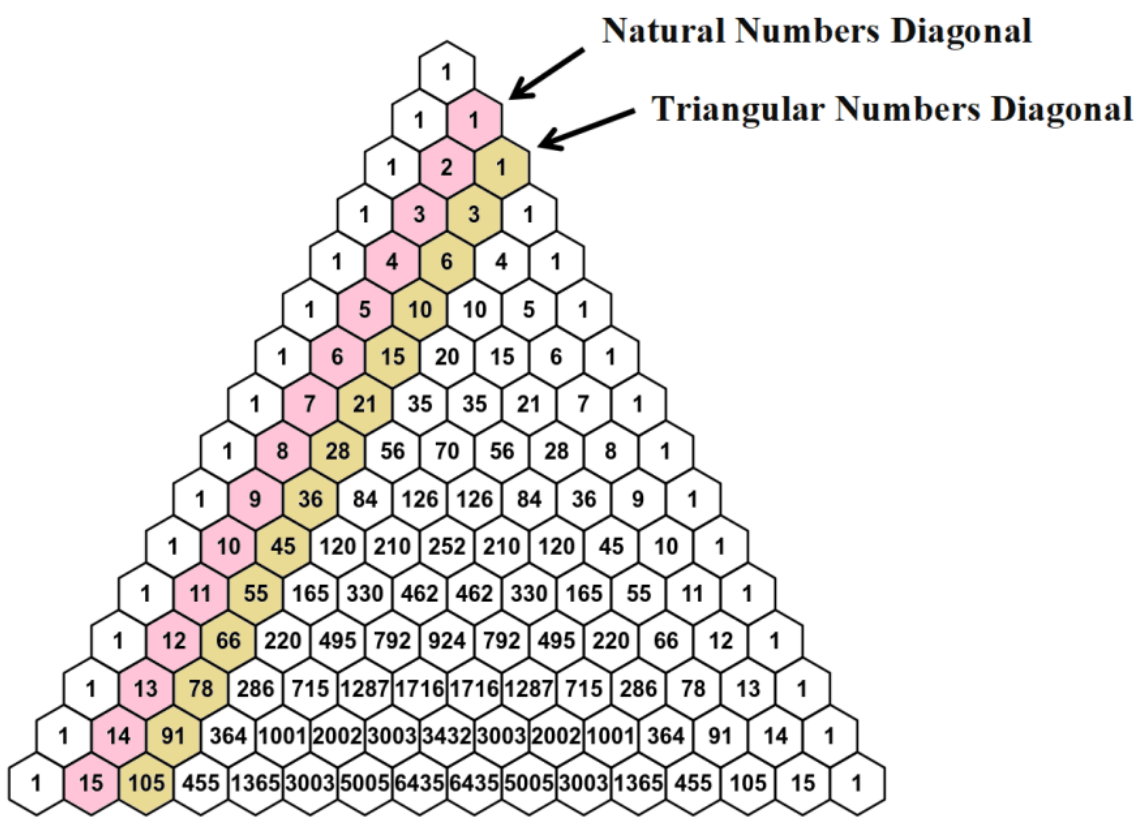

Figure 1: TRIADS of Metallic Means and the Diagonals of Pascal's Triangle 
If $\mathbf{m}$ and $\mathbf{n}$ are two consecutive integers from the Natural Numbers Diagonal : $\mathbf{m}-\mathbf{n}=\mathbf{1}$,

then the integer, say $\mathbf{x}$, on the Triangular Numbers Diagonal, adjacent to $\mathbf{n}$ and $\mathbf{m}$, gives value of $\mathbf{k}$ by an imperical formula :

If $\mathbf{n}$ is $\left(\begin{array}{l}n \\ 1\end{array}\right)$ i.e. the First element in $n^{\text {th }}$ Row. As $\mathbf{n}$ is on Natural Number Diagonal, it's on $n^{\text {th }}$ Row. And $\mathrm{m}$ is $\left(\begin{array}{c}n+1 \\ 1\end{array}\right)$;

and $\mathbf{X}$ is $\left(\begin{array}{c}n+1 \\ 2\end{array}\right)$ i.e. the $\mathrm{n}^{\text {th }}$ Triangular Number

then, $\mathbf{k}=\mathbf{2} \mathbf{x}+\mathbf{4}$; as shown below in Figure 2.

$$
(\mathrm{m}-\mathrm{n})=1
$$

$\mathbf{m} \& \mathbf{n}$ are Consecutive Integers on

Natural Numbers Diagonal.

Then, the Adjecent Integer $\mathrm{X}$ from

Triangular Numbers Diagonal gives value of $\mathbf{k}$ :

$$
k=2 x+4
$$

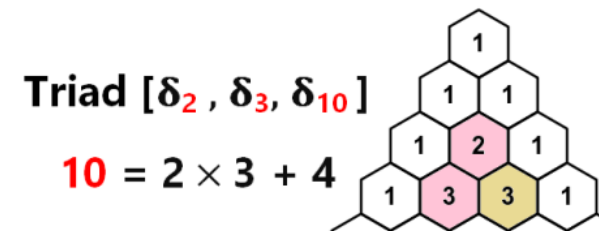

Triad $\left[\boldsymbol{\delta}_{5}, \boldsymbol{\delta}_{6}, \boldsymbol{\delta}_{34}\right]$
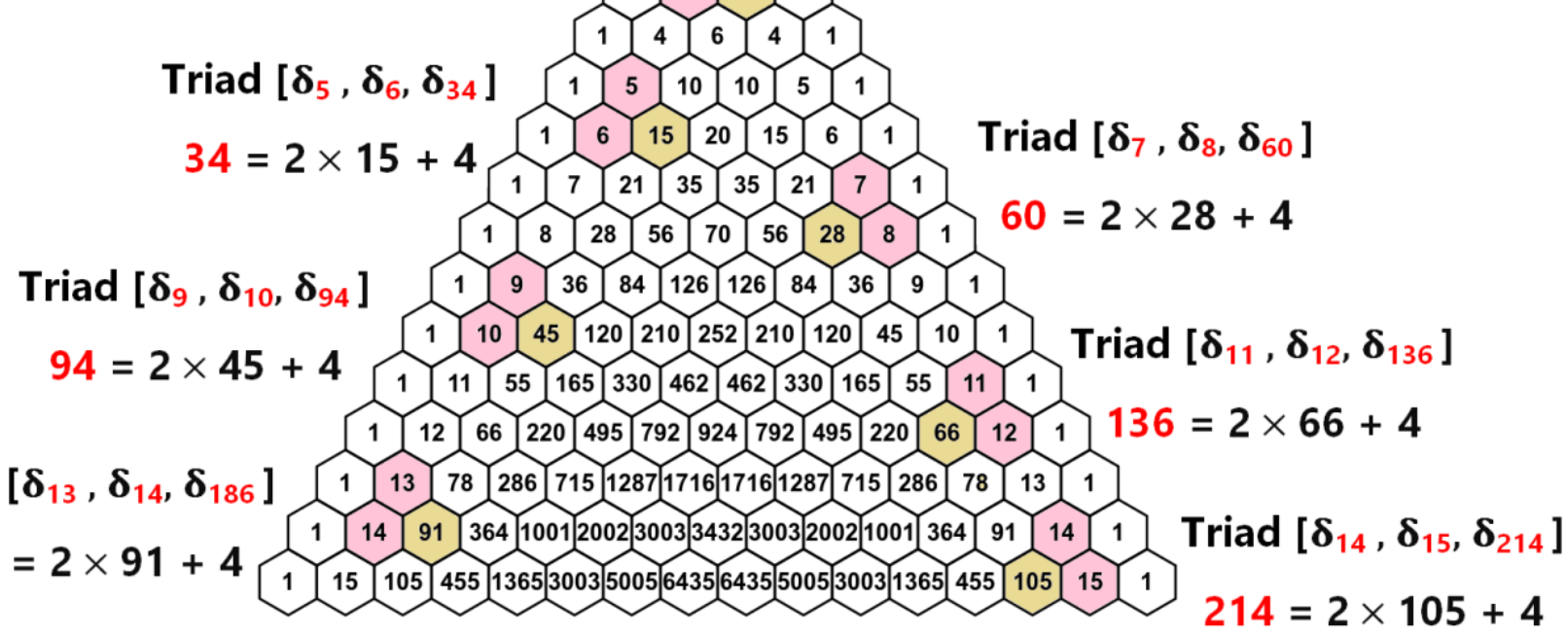

Figure 2: TRIADS of Metallic Means with $\mathbf{m}-\mathbf{n}=\mathbf{1}$, and calculating the value of $\mathbf{k}$ from Pascal's Triangle 
Similarly, the TRIADS of Metallic Means with non-consecutive integers $\mathbf{n}$ and $\mathbf{m}$ can also be derived from the Pascal's Triangle, as described below.

For instance, if $\mathbf{m}-\mathbf{n}=\mathbf{2}$,

then the couple of integers, say $\mathbf{x}$ and $\mathbf{y}$, on the Triangular Numbers Diagonal, adjacent to $\mathbf{n}$ and $\mathbf{m}$ respectively, gives value of $\mathbf{k}$ :

If $\mathbf{n}$ is $\left(\begin{array}{c}n \\ 1\end{array}\right)$ and $\mathbf{m}$ is $\left(\begin{array}{c}n+2 \\ 1\end{array}\right)$

then $\mathbf{X}$ is $\left(\begin{array}{c}n+1 \\ 2\end{array}\right)$ and $\mathbf{y}$ is $\left(\begin{array}{c}n+2 \\ 2\end{array}\right)$

And here $\mathbf{K}=\frac{(\mathbf{x}+\mathbf{y})+\mathbf{3}}{\mathbf{2}}$; as illustrated below in Figure $\mathbf{3}$

$$
(\mathbf{m}-\mathbf{n})=2
$$

Then, the Integers $\mathrm{X}$ and $\mathrm{Y}$ from

Triangular Numbers Diagonal give value of $\mathbf{k}$ :

$$
\mathbf{k}=\frac{(\mathrm{x}+\mathrm{y})+3}{2}
$$

\section{Triad $\left[\boldsymbol{\delta}_{2}, \boldsymbol{\delta}_{4}, \boldsymbol{\delta}_{6}\right]$}

$$
6=\frac{(3+6)+3}{2}
$$

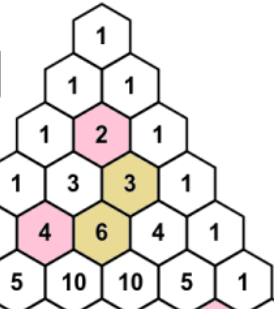

Triad $\left[\boldsymbol{\delta}_{8}, \boldsymbol{\delta}_{10}, \boldsymbol{\delta}_{42}\right]$

$$
\text { 1) } 5 \text { 10 } 10 \text { (0) } 10
$$

$$
42=\frac{(36+45)+3}{2}
$$

Triad $\left[\boldsymbol{\delta}_{12}, \boldsymbol{\delta}_{14}, \boldsymbol{\delta}_{86}\right]$ (1)

$$
86=\frac{(78+91)+3}{2}
$$

Figure 3: TRIADS of Metallic Means with $\mathbf{m}-\mathbf{n}=\mathbf{2}$, and calculating the value of $\mathbf{k}$ from Pascal's Triangle 
Similarly, the TRIADS of Metallic Means with higher values of $(\mathbf{m}-\mathbf{n})$ can also be derived from the Pascal's Triangle, in similar manner.

\section{Consider $\mathbf{m}-\mathbf{n}=\mathbf{4}$}

i.e. $\mathrm{n}$ is $\left(\begin{array}{c}n \\ 1\end{array}\right)$ and $\mathrm{m}$ is $\left(\begin{array}{c}n+4 \\ 1\end{array}\right)$;

In this case, the integers $\mathbf{w}, \mathbf{x}, \mathbf{y}$ and $\mathbf{z}$ on the Triangular Numbers Diagonal, lying between $\mathbf{n}$ and $\mathbf{m}$, with Row numbers from $(n+1)$ to $(m)$ i.e. Triangular Numbers from $\left(\begin{array}{c}n+1 \\ 2\end{array}\right)$ to $\left(\begin{array}{c}n+4 \\ 2\end{array}\right)$ give the value of $\mathbf{k}$ as:

$\mathbf{k}=\frac{(\mathbf{w}+\mathbf{x}+\mathbf{y}+\mathbf{z})-\mathbf{2}}{\mathbf{8}} ;$ as shown below in Figure 4

$$
(m-n)=4
$$

Then, the Integers $\mathrm{W}, \mathrm{X}, \mathrm{Y}$ and $\mathrm{Z}$ from

Triangular Numbers Diagonal give value of $\mathbf{k}$ :

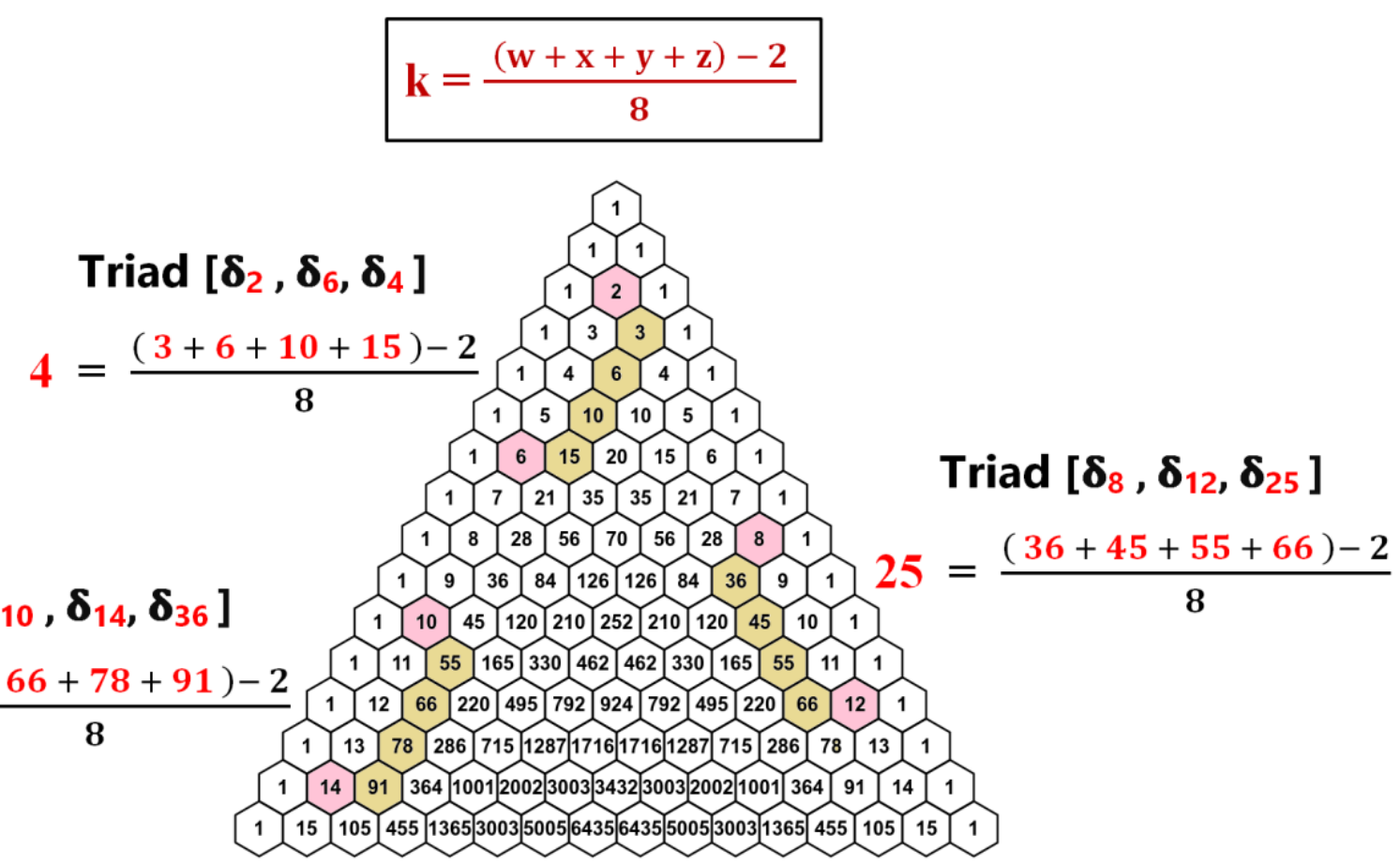

Figure 4: TRIADS of Metallic Means with $\mathbf{m}-\mathbf{n}=\mathbf{4}$, and calculating the value of $\mathbf{k}$ from Pascal's Triangle 
Thus, the Integers on the Triangular Numbers Diagonal of Pascal's Triangle, with Row numbers from $(n+1)$ to $(m)$ give the value of $\mathrm{K}$.

Also, for $\mathbf{m}-\mathbf{n}=\mathbf{4}$, the TRIAD can be derived from the Pascal's Triangle by another method.

The Integer, say $\mathbf{P}$, on Triangular Numbers Diagonal, in Row $(\mathbf{n}-\mathbf{1})$ can give the precise value of $\mathbf{k}$ by another imperical formula :

If $\mathrm{n}$ is $\left(\begin{array}{l}n \\ 1\end{array}\right)$ and $\mathrm{m}$ is $\left(\begin{array}{c}n+4 \\ 1\end{array}\right)$; then $\mathrm{p}$ is $\left(\begin{array}{c}n-1 \\ 2\end{array}\right)$

and, $\mathbf{k}=\mathbf{P}+\frac{(\mathbf{1 0}-\mathbf{n}) \times \mathbf{n}}{4}$

For illustration, consider following Figure 5.

$$
(m-n)=4
$$

Then, the Integer $P$ from Triangular Numbers

Diagonal, in Row $(\mathbf{n}-1)$ gives value of $k$ :

$$
\mathbf{k}=\mathbf{P}+\frac{(10-\mathbf{n}) \times \mathbf{n}}{4}
$$

Triad $\left[\boldsymbol{\delta}_{4}, \boldsymbol{\delta}_{8}, \boldsymbol{\delta}_{9}\right]$

$9=3+\frac{(10-4) \times 4}{4}$
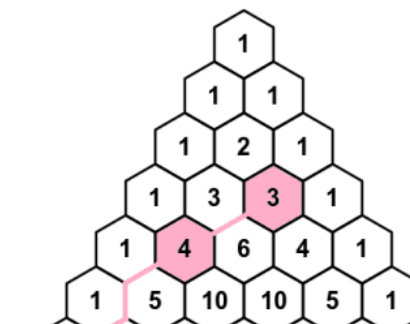

16 15 20 15 6 (1)

Triad $\left[\boldsymbol{\delta}_{12}, \boldsymbol{\delta}_{16}, \boldsymbol{\delta}_{49}\right]$
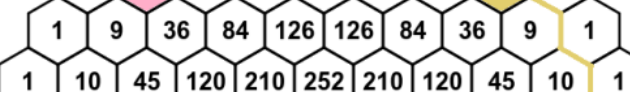

$25=21+\frac{(10-8) \times 8}{4}$

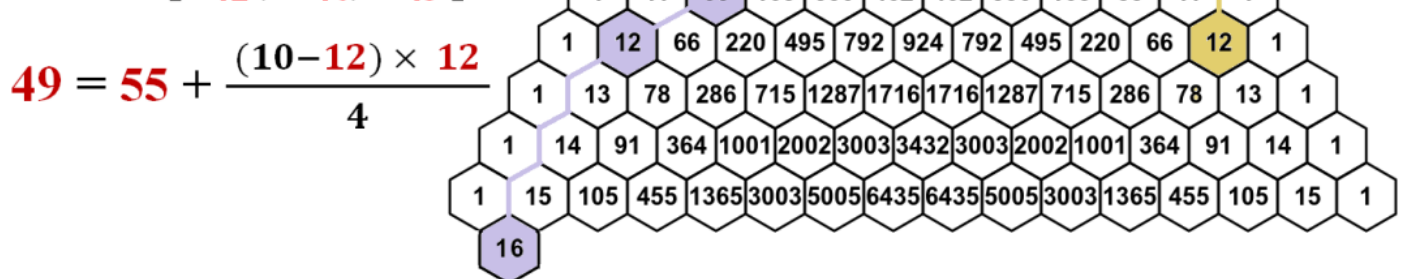

Figure 5: TRIADS of Metallic Means with $\mathbf{m}-\mathbf{n = 4}$, and calculating the value of $\mathbf{k}$ from Pascal's Triangle 
Thus, the Integers on the Triangular Numbers Diagonal of Pascal's Triangle give the value of $K$ that forms a TRIAD of Metallic Means with $\mathrm{n}$ and $\mathrm{m}$ from the Natural Numbers Diagonal : $\left[\boldsymbol{\delta}_{\mathrm{n}}, \boldsymbol{\delta}_{\mathrm{m}}, \boldsymbol{\delta}_{\mathrm{k}}\right]$; the Three Metallic Ratios precisely befitting the Formulae:

$\frac{\boldsymbol{\delta}_{\mathrm{m}} \times \boldsymbol{\delta}_{\mathrm{n}}+\mathbf{1}}{\boldsymbol{\delta}_{\mathrm{m}}-\boldsymbol{\delta}_{\mathrm{n}}}=\boldsymbol{\delta}_{\mathrm{k}} \quad$ and $\quad \frac{\boldsymbol{\delta}_{\mathrm{k}} \times \boldsymbol{\delta}_{\mathrm{n}}+\mathbf{1}}{\boldsymbol{\delta}_{\mathrm{k}}-\boldsymbol{\delta}_{\mathrm{n}}}=\boldsymbol{\delta}_{\mathrm{m}} \quad$ and also $\quad \frac{\boldsymbol{\delta}_{\mathrm{k}} \times \boldsymbol{\delta}_{\mathrm{m}}-\mathbf{1}}{\boldsymbol{\delta}_{\mathrm{k}}+\boldsymbol{\delta}_{\mathrm{m}}}=\boldsymbol{\delta}_{\mathbf{n}}$

Hence, the Pascal's Triangle and its idiosyncratic array of numbers, can provide the abovementioned TRIADS of Metallic Means, by various computational methods, using the integers on its various Diagonals.

On the last note, it is worth mentioning here that several such new intriguing properties of Metallic Ratios and these TRIADS of Metallic Means are described in details in the works mentioned in the References. For instance, these TRIADS are found to be closely associated with Pythagorean Triples and Pythagorean Primes [2][11]; the geometric substantiation of Metallic Ratios and their TRIADS [2] [6] [7] [8] [9] [10]; and special positions of Integers 3, 6 and 9 in the realm of Metallic Means [2][12]. Further, all mathematical formulae those provide the precise relations between different Metallic Means are described in the work mentioned in Reference [1].

\section{Conclusion:}

This paper introduced the close correspondence between Pascal's Triangle and Metallic Means. The TRIADS of Metallic Means are produced by an imperical formula that provides the precise relations between different Metallic Ratios. And, such TRIADS of Metallic Means can also be substantiated with Pascal's Triangle, as described in this paper.

\section{References:}

[1] Rajput, Chetansing (2021). Metallic Ratios : Beyond the Golden Ratio; The Mathematical Relationships between different Metallic Means. JOURNAL OF ADVANCES IN MATHEMATICS, 20, 158-166. https://doi.org/10.24297/jam.v20i.9023

[2] Rajput, Chetansing (2021). "Metallic Means : Beyond the Golden Ratio, New Mathematics and Geometry of all Metallic Ratios based upon Right Triangles, The Formation of the Triples of Metallic Means, And their Classical Correspondence with Pythagorean Triples and $p \equiv 1$ (mod 4) Primes, Also the Correlation between Metallic Numbers and the Digits 36 9", JOURNAL OF ADVANCES IN MATHEMATICS, 20, 250-266. https://doi.org/10.24297/jam.v20i.9056

[3] Vera W. de Spinadel (1999). The Family of Metallic Means, Vismath 1(3) from Mathematical Institute of Serbian Academy of Sciences and Arts.

[4] Weisstein, Eric W. "Table of Silver means". MathWorld.

[5] "An Introduction to Continued Fractions: The Silver Means", maths.surrey.ac.uk.

[6] Rajput, Chetansing (2021). "A Right Angled Triangle for each Metallic Mean". Journal of Advances in Mathematics. 20: 32-33. https://en.wikipedia.org/wiki/Metallic mean\#cite note-15

[7] Rajput, Chetansing (2021). Golden Ratio. JOURNAL OF ADVANCES IN MATHEMATICS, 20, $19-42$. https://doi.org/10.24297/jam.v20i.8945 
[8] Rajput, Chetansing (2021). Metallic Means and Right Triangles: The Geometric Substantiation of all Metallic Ratios JOURNAL OF ADVANCES IN MATHEMATICS, 20, 167-173. https://doi.org/10.24297/jam.v20i.9029

[9] Rajput, Chetansing (2021). Golden Ratio and other Metallic Means: The Geometric Substantiation of all Metallic Ratios with Right Triangles. JOURNAL OF ADVANCES IN MATHEMATICS, 20, $174-187$. https://doi.org/10.24297/jam.v20i.9034

[10] Rajput, Chetansing (2021). Metallic Ratio Triads, The Mathematical and Geometric Relations between different Metallic Means, Metallic Numbers and the Right Angled Triangles. JOURNAL OF ADVANCES IN MATHEMATICS, 20, 167-173. https://doi.org/10.24297/jam.v20i.9077

[11] Rajput, Chetansing (2021). Metallic Ratios, Pythagorean Triples \& Pythagorean Primes: New Mathematics and Geometry of Metallic Means,Metallic Numbers, Right Triangles and the Pythagoras Theorem. JOURNAL OF ADVANCES IN MATHEMATICS, 20, 167-173. https://doi.org/10.24297/jam.v20i.9075

[12] Rajput, Chetansing (2021). Metallic Ratios and the Digits 36 9, Mathematical Relations between different Metallic Means,_And the Special Significance of Digits 3, 6, 9 in the realm of Metallic Numbers. JOURNAL OF ADVANCES IN MATHEMATICS, 20, 167-173. https://doi.org/10.24297/jam.v20i.9076

\begin{tabular}{|l|l|}
\hline Select Lecture Videos of Author: & Contacts: \\
1) https://youtu.be/vBfVDaFnA2k & Website: https://goldenratiorajput.com/ \\
2) https://youtu.be/74uF4sBqYjs & Email: chetansingkrajput@gmail.com \\
3) https://youtu.be/raosniXwRhw & Email: chetansingkrajput1129@gmail.com \\
4) https://youtu.be/Qh2B1tMl8Bk & Contacts: (+91) 7057521129 \\
\hline
\end{tabular}

